02

\title{
Спектрально-люминесцентные свойства разнолигандных комплексных соединений европия(III) с о-метоксибензойной кислотой и фосфорсодержащими нейтральными лигандами
}

\author{
(C) И.В. Калиновская
}

Институт химии Дальневосточного отделения РАН, 690022 Владивосток, Россия

e-mail: kalinovskaya@ich.dvo.ru

Поступила в редакцию 26.12.2019 г.

В окончательной редакции 26.12.2019 г.

Принята к публикации 12.02.2020 г.

\begin{abstract}
Изучены спектрально-люминесцентные свойства комплексных соединений европия(III) с $o$-метоксибензойной кислотой и фосфорсодержащими нейтральными лигандами островного строения состава $\mathrm{Eu}(\mathrm{MOBA})_{3} \cdot 3 \mathrm{H}_{2} \mathrm{O}$ и $\mathrm{Eu}(\mathrm{MOBA})_{3} \cdot L$, где МОВА - $o$-метоксибензойная кислота, $L-h m p a$ (гексаметилфосфортриамид), tрро (трифенилфосфиноксид), Et 6 ра (гексаэтилфосфотриамид). Установлено, что передача энергии возбуждения к иону европия осуществляется как с уровней o-метоксибензойной кислоты, так и с уровней фосфорсодержащих нейтральных лигандов. Проведен анализ электронных спектров поглощения, спектров возбуждения люминесценции и штарковской структуры электронных переходов ${ }^{5} D_{0}-{ }^{7} F_{j}(j=0-2)$ в спектрах люминесценции разнолигандных комплексных $о$-метоксибензоатов европия(III). Наибольшей интенсивностью люминесценции обладает метоксибензоат европия(III) с трифенилфосфиноксидом.
\end{abstract}

Ключевые слова: люминесценция, соединения европия, $о$-метоксибензойная кислота, спектры возбуждения люминесценции.

DOI: $10.21883 /$ OS.2020.06.49397.352-19

Фотоустойчивые координационные соединения редкоземельных элементов с карбоновыми кислотами, азот- и фосфорсодержащими нейтральными лигандами и светотрансформирующие полимерные материалы на их основе могут быть использованы в различных устройствах молекулярной электроники, в оптоэлектронике, органических светоизлучающих диодах и лазерах [1-7]. К достоинствам люминесцирующих ароматических карбоксилатов лантаноидов относятся высокая химическая и термическая стабильность, стабильность при облучении светом, а также возможность изменения их состава, строения и физико-химических свойств варьированием координации лигандов. Перспективными являются разнолигандные комплексные соединения европия(III) с o-метоксибензойной кислотой. Так, разнометальный $o$-метоксибензоат тербий-иттрий с 1,10-фенантролином был успешно использован в качестве компонентов, образующих светоизлучающие слои в электролюминесцентных устройствах [8]. Оптимизация спектроскопических характеристик соединений редкоземельных элементов за счет изменения фрагментов их кристаллических структур является важным этапом в изготовлении интенсивнолюминесцентных лантаноидных материалов, которые могут быть использованы для получения оптических материалов.

Изучены спектрально-люминесцентные свойства соединений европия с метоксибензойными кислотами и азотсодержащими нейтральными лигандами [9-14], ком- плексные соединения европия с фосфорсодержащими нейтральными лигандами получены не были.

В настоящем сообщении представлены результаты изучения состава, строения, термических свойств разнолигандных комплексных соединений европия(III) с $o$-метоксибензойной кислотой и фосфорсодержащими нейтральными лигандами состава $\mathrm{Eu}(\mathrm{MOBA})_{3} \cdot L$, где МОВА - анион $o$-метоксибензойной кислоты, $L-$ гексаэтилфосфотриамид $\left(E t_{6} p a\right)$, гексаметилфосфотриамид ( hтра), трифенилфосфиноксид (tppo).

\section{Экспериментальная часть}

Для синтеза разнолигандных комплексных соединений европия с $о$-метоксибензойной кислотой и фосфорсодержащими нейтральными лигандами использовали следующие реактивы марки „ч“: шестиводный хлорид европия(III), o-метоксибензойную кислоту, фосфорсодержащие лиганды (гексаэтилфосфотриамид, гексаметилфосфотриамид, трифенилфосфиноксид). $O$-метоксибензойную кислоту перекристаллизовывали из $90 \%$ этанола.

$O$-метоксибензоаты европия(III) с фосфорсодержащими нейтральными лигандами получали по следующей методике: к $1 \mathrm{mmol}$ шестиводного хлорида европия(III), растворенного в минимальном количестве дистиллированной воды, приливали $3 \mathrm{mmol} o$-метоксибензойной кислоты и $1 \mathrm{mmol}$ нейтрального фосфорсодержащего лиганда, растворенных в $15 \mathrm{ml}$ 90\%-этанола. 10\%- 


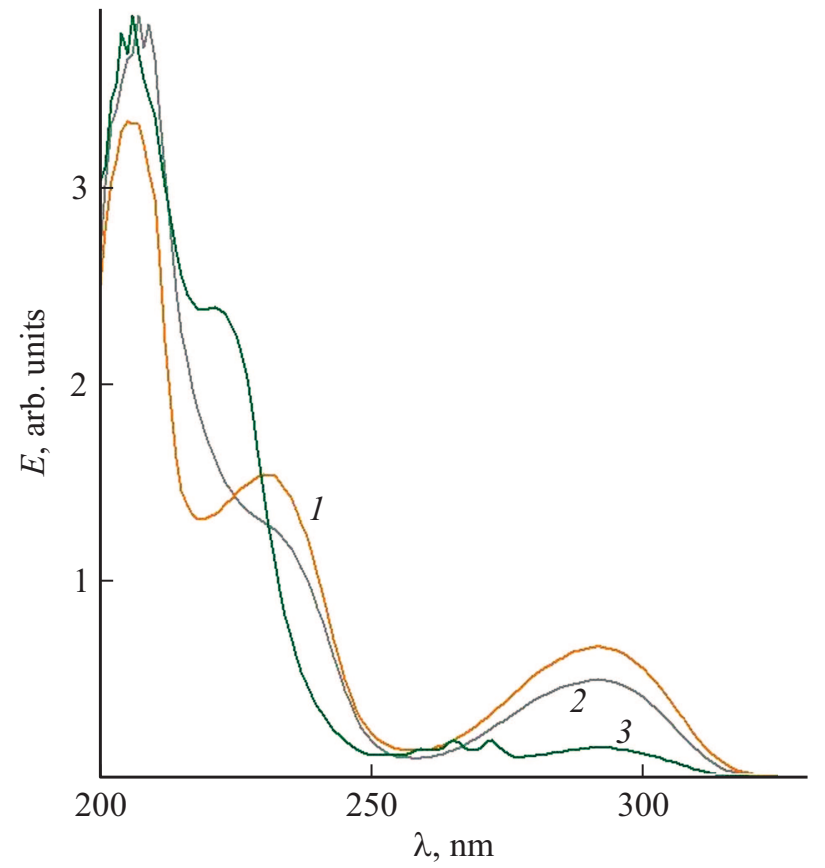

Рис. 1. Электронные спектры поглощения $10^{-4}$ М-растворов $\left(\mathrm{C}_{2} \mathrm{H}_{5} \mathrm{OH}\right)$ p-MOBA (1), $\mathrm{Eu}(\mathrm{MOBA})_{3} \cdot h m p a$ (2), $\mathrm{Eu}(\mathrm{MOBA})_{3} \cdot$ tppo $(3)$.

раствором аммиака доводили $\mathrm{pH}$ до 5.5-6.0 и оставляли стоять до образования осадка. Осадок отфильтровывали, промывали водно-этанольной смесью, сушили на воздухе. Полученные комплексные соединения европия(III) представляют собой мелкокристаллические порошки желтого цвета, не растворимые в большинстве неполярных растворителях.

Спектры возбуждения люминесценции и люминесценции регистрировали на приборе RF-5301 Shimadzu.

Электронные спектры поглощения - на спектрометpe RF-2550 Shimadzu. Концентрация соединения в 96\%этаноле равна $10^{-4} \mathrm{~mol} / \mathrm{l}$.

\section{Результаты и их обсуждение}

Полученные нами электронные спектры поглощения синтезированных координационных соединений европия(III) с $о$-метоксибензойной кислотой и фосфорсодержащими нейтральными лигадами приведены на рис. 1. Как видно из рис. 1, комплексообразование приводит к изменению положения полосы, соответствующей $\pi \pi^{*}$-переходу $o$-метоксибензойной кислоты $\left(\lambda_{\text {макс }}=225-235 \mathrm{~nm}\right)$. Для полученных разнолигандных $o$-метоксибензоатов европия(III) характерен более сложный вид электронных спектров поглощения, чем для о-метоксибензойной кислоты. В электронных спектрах поглощения (ЭСП) синтезированных разнолигандных $о$ метоксибензоатов с фосфорсодержащими нейтральными лигандами наблюдаются дополнительные полосы поглощения, характерные для координированных фосфорсодержащих нейтральных молекул лигандов. Так, в спектре $\mathrm{Eu}(\mathrm{MOBA})_{3} \cdot$ tрро отчетливо проявляется три полосы поглощения tрро с $\lambda_{\text {макс }}=240-276 \mathrm{~nm}$. Также в ЭСП данного комплексного соединения полоса поглощения $о$-метоксибензойной кислоты с $\lambda_{\text {макс }}=290 \mathrm{~nm}$ изменилась, сдвинута в более длинноволновую область по сравнению с ее положением в спектре „свободной“ $о$-метоксибензойной кислоты на 4-5 nm, которая обязана синглетному $\left(S \pi \pi^{*}\right)$-переходу $[15,16]$. $\mathrm{B}$ спектрах поглощения соединений $\mathrm{Eu}(\mathrm{MOBA})_{3} \cdot h m p a$, $\mathrm{Eu}(\mathrm{MOBA})_{3} \cdot E t_{6} p a$ полосы поглощения нейтральных лигандов (гексаметилфосфотриамида и гексаэтилфосфотриамида), $o$-метоксибензойной кислоты накладываются в области $220-235 \mathrm{~nm}$.

Спектры возбуждения люминесценции разнолигандых координационных соединений европия(III) с $о$-метоксибензойной кислотой с фосфорсодержащими нейтральными лигандами состоят из широкой высокочастотной полосы, обусловленной полосами поглощения координируемых лигандов и узких линий $f-f$-переходов ионов европия(III) (рис. 2). В спектрах возбуждения люминесценции полученных нами разнолигандных $o$-метоксибензоатов присутствуют полосы $\pi \pi^{*}$-переходов $o$-метоксибензойной кислоты и соответствующего фосфорсодержащего нейтрального лиганда, что приводит к передачи энергии как с триплетных уровней $o$-метоксибензойной кислоты, так и с уровней нейтрального фосфорсодержащего лиганда на европий.

Синтезированные новые разнолигандные o-метоксибензоаты европия(III) люминесцируют (в твердом состоянии и в растворе) как при комнатной температуре, так и при $77 \mathrm{~K}$ красным цветом (рис. 3). Общий характер спектров люминесценции в ряду полученных о-метоксибензоатов европия(III) с фосфорсодержащими нейтральными лигандами сохраняется. В спектрах люминесценции комплексных соединений европия(III)

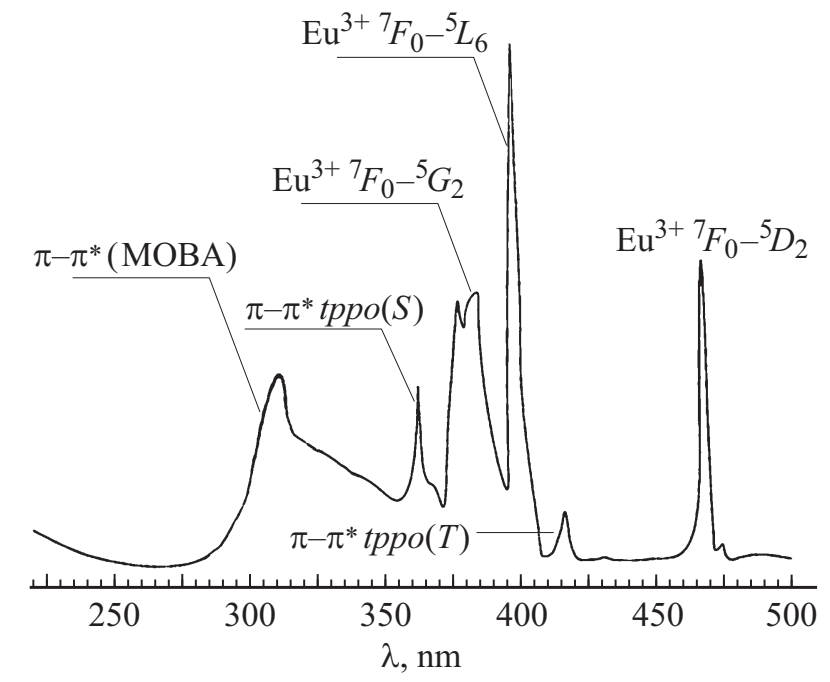

Рис. 2. Спектр возбуждения люминесценции $\mathrm{Eu}(\mathrm{MOBA})_{3} \cdot$ tр ро при $293 \mathrm{~K}, \lambda_{\text {per }}=612 \mathrm{~nm}$. 


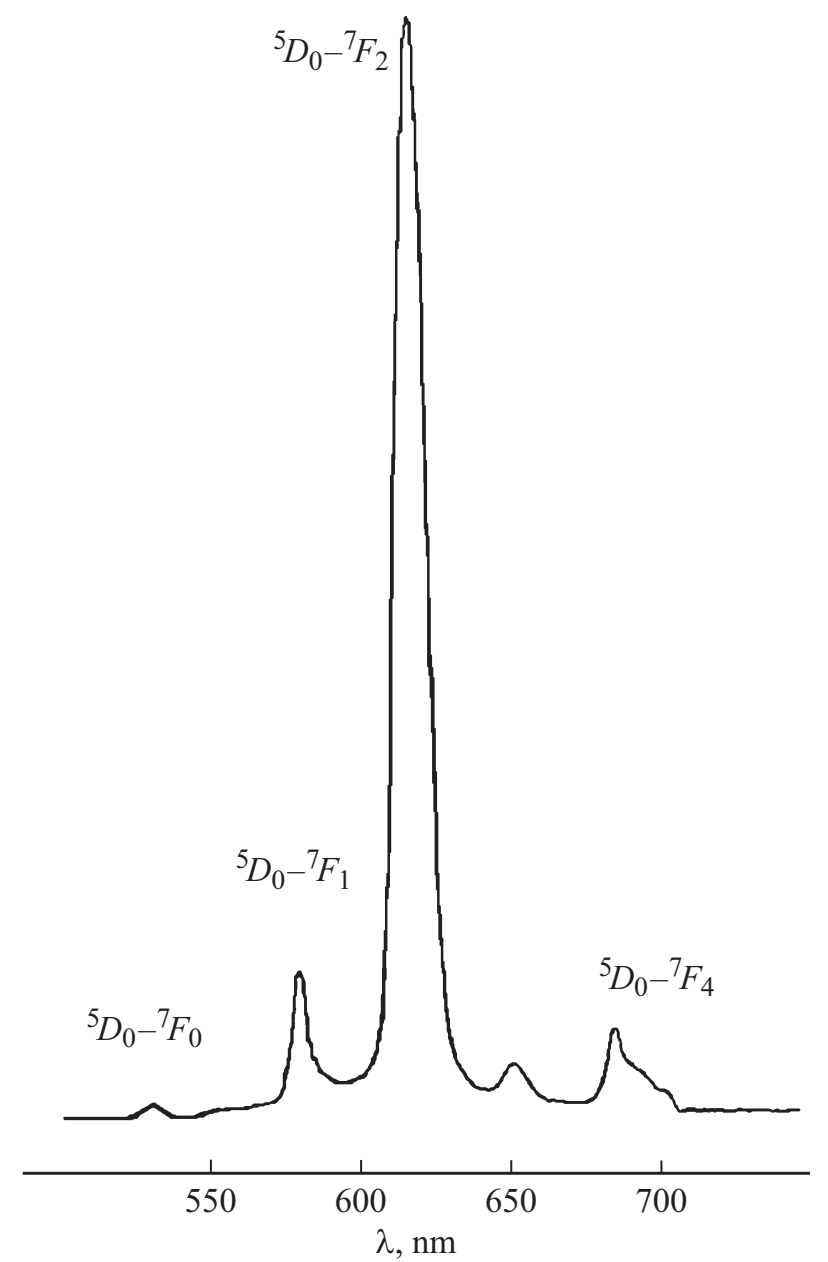

Pис. 3. Спектры люминесценции $\mathrm{Eu}(\mathrm{MOBA})_{3} \cdot t$ рро при $293 \mathrm{~K}$

наиболее интенсивные полосы относятся к электродипольному ${ }^{5} D_{0}-{ }^{7} F_{2}$-переходу. Данный переход является чувствительным к замене нейтрального лиганда в разнолигандных комплексах: наблюдается перераспределение интенсивностей отдельных линий и изменения в структуре расщепления штарковских компонент ${ }^{7} F_{2}$ уровня. В спектрах люминесценции полученных новых разнолигандных комплексных соединений в области электродипольного ${ }^{5} D_{0}-{ }^{7} F_{2}$-перехода наблюдается до трех компонент. Интенсивность полос магнитодипольного перехода ${ }^{5} D_{0}-{ }^{7} F_{1}$ практически в три-пять раз ниже интенсивности полос электродипольного ${ }^{5} D_{0}-{ }^{7} F_{2}$ перехода. Расщепление двух крайних полос магнитодипольного ${ }^{5} D_{0}-{ }^{7} F_{1}$-перехода существенно меняется при замене нейтрального фосфорсодержащего лиганда, что указывает на вхождение его в координационную сферу иона европия(III). Заметно интенсивными в спектре люминесценции являются полосы электродипольного перехода ${ }^{5} D_{0}-{ }^{7} F_{4}$. Они сопоставимы по интенсивности с интенсивностью полос магнитодипольного перехода ${ }^{5} D_{0}-{ }^{7} F_{1}$.
Для полученных нами разнолигандных комплексных соединений европия(III) были определены значения интегральных интенсивностей ${ }^{5} D_{0}-{ }^{7} F_{2}$-перехода иона европия(III). Было обнаружено увеличение интенсивности в спектре люминесценции европия при переходе от гидрата $о$-метоксибензоата европия(III) к комплексным соединениям с фосфорсодержащими нейтральными лигандами. Для $о$-метоксибензоата европия(III) с трифенилфосфиноксидом характерно максимальное значение интенсивности люминесценции, обусловленное высокими донорными свойствами нейтрального лиганда трифенилфосфиноксида, наличием более развитой $\pi$-сопряженной системы эффективных поглотителей ультрафиолетового света и отсутствием молекул воды в координационной сфере комплексного соединения.

Сравнительный анализ интенсивности люминесценции разнолигандных комплексных $o$-метоксибензоатов европия(III) с фосфорсодержащими нейтральными лигандами и изученных раннее $о$-метоксибензоатов с азотсодержащими нейтральными лигандами (нами были синтезированы и изучены люминесцентные свойства $o$-метоксибензоатов европия с 1,10-фенантролином и 2,2-дипиридилом) указывает на то, что интенсивность люминесценции соединений с фосфорсодержащии нейтральными лигандами выше на 10-20\%.

Таким образом, нами синтезированы новые люминесцирующие разнолигандные комплексные $o$-метоксибензоаты европия(III) с фосфорсодержащими нейтральными лигандами. Показано, что передача энергии возбуждения к иону европия осуществляется как с уровней $o$ метоксибензойной кислоты, так и с уровней нейтральных фосфорсодержащих лигандов. Проведен анализ электронных спектров поглощения, спектров возбуждения люминесценции и штарковской структуры ${ }^{5} D_{0}-{ }^{7} F_{j}$ $(j=0-2)$ электронных переходов в спектрах люминесценции комплексных $о$-метоксибензоатов европия(III).

\section{Финансирование работы}

Работа выполнена при финансовой поддержке Минобрнауки, номер темы государственного задания 02652014-0001.

\section{Конфликт интересов}

Автор заявляет, что у нее нет конфликта интересов.

\section{Список литературы}

[1] Bunzli J.-C.G., Eliseeva S.V. // Chem. Sci. 2013. V. 4. N 5. P. 1913.

[2] Binnemans K. // Handbook on the Physics and Chemistry of Rare Earths. Elsevier, 2005. V. 35. P. 107-272.

[3] Hasegawa Y., Nakanishi T. // RSC. Adv. 2015. V. 5. P. 338.

[4] Zhang J., Wang R., Bai J., Wang S. // J. Rare Earths. 2002. V. 20. N 5. P. 449. 
[5] Zhang J., Wang R., Yang H., Chin. // J. Anal. Chem. 2003. V. 31. N 4. P. 472.

[6] Kataoka H., Kitano T., Takizawa T., Hirai Y., Nakanishi T., Hasegawa Y. // J. Alloys Compd. 2014. V. 601. P. 293.

[7] Hui-Juan Sun., Ai-Ling Wang., Hai-Bin Chu., YoungLiang Zhao // Luminescence. 2015. N 30. P. 131.

[8] Shi Y., Deng Z., Xiao J., Xu D., Chen Z., Wang R. // J. Lumin. 2007. V. 122-123. P. 272.

[9] Wang R., Li L., Jin L., Lu S. // J. Rare Earths. 1998. V. 16. P. 445.

[10] Li X., Bian Z., Jin L., Lu S., Huang S. // J. Mol. Struct. 2000. V. 522. P. 117.

[11] Li X., Zou Y.-Q. // Z. Kristallogr. New Cryst. Struct. 2003. V. 218. P. 445.

[12] Gao Z.-H., Wang H., He J.-Y., Wang R.-F. //Acta Cryst. E. 65. 2009. V. 16. P. 1240.

[13] Ma R.X., Chen Z.-M., Gao Z.-H., Wang S.-P., Wang R.-F., Zhang J.-J. // Synth. Met. 2009. V. 159. P. 1272.

[14] Jin L., Wang R., Li L., Lu S., Huang S. // Polyhedron. 1998. V. 18. P. 487.

[15] Калиновская И.В., Карасев В.Е., Пяткина А.Н. // Журн. неорг. химии. 1999. Т. 44. С. 432.

[16] Калиновская И.В., Задорожная А.Н., Карасев В.Е. // Журн. физ. химии. 1987. Т. 34. № 6. С. 1175. 